\title{
MODELAGEM DE ESTRUTURAS METÁLICAS IMPRESSAS EM IMPRESSORAS 3D PARA APOIO DIDÁTICO NAS DISCIPLINAS QUE ABORDEM CONSTRUÇÕES EM AÇO
}

DOI: 10.37702/2175-957X.COBENGE.2021.3469

Matheus Souza Cavalcante - wathew@hotmail.com Instituto Federal de Mato Grosso Campus Cuiabá Rua Zulmira Canavarros 95 78005-390 - Cuiabá - MT

Renan Guides Diniz de Barros - renanguides@hotmail.com Instituto Federal de Mato Grosso Campus Cuiabá Rua Zulmira Canavarros 95 78005-390 - Cuiabá - MT

Carlos Gabriel Assumpção - assumpcao001@gmail.com Instituto Federal de Mato Grosso Campus Cuiabá Rua Zulmira Canavarros 95 78005-390 - Cuiabá - MT

Ângela Fátima da Rocha - angela.rocha@cba.ifmt.edu.br Instituto Federal de Mato Grosso Campus Cuiabá Rua Zulmira Canavarros 95 78005-390 - Cuiabá - MT

Ernany Paranaguá da Silva - ernany@cba.ifmt.edu.br Instituto Federal de Mato Grosso Campus Cuiabá Rua Zulmira Canavarros 95 78005-390 - Cuiabá - MT

Mychelle Fabiane Carvalho Bueno Sato - mychellefabiane@hotmail.com Instituto Federal de Mato Grosso Campus Cuiabá Av Presidente Arthur Bernardes 580 78125-100 - Varzea Grande - MT

Resumo: A modelagem de estruturas metálicas impressas em impressoras 3D 
para apoio didático enriqueceu as atividades das disciplinas de Sistemas Construtivos em Aço e Tecnologias das Construções, abordando de forma mais atrativa e inovadora os conteúdos ministrados. No decorrer dessas disciplinas inúmeros são os tópicos a serem estudados, como por exemplo, as ligações aparafusadas e ou soldadas dos sistemas estruturais em aço, a simulação em maquete da montagem do galpão despertou a curiosidade dos alunos. Como essas disciplinas não possuem laboratório no Campus Cuiabá, Octayde Jorge da Silva, as modelagens via softwares, o conhecimento prático das impressões $3 D$ e a simulação da montagem ocuparam um espaço fundamental no aprendizado e na valorização desses futuros profissionais. Sendo assim, a modelagem de estruturas metálicas em impressoras 3D promoveu a verticalização do ensino no IFMT, aproximando o ensino médio integrado em Edificações dos cursos superiores em Engenharia de Automação e Controle e Tecnologia em Construção de Edifícios. $O$ projeto participou do evento Workif promovido pela instituição, que divulgou as pesquisas do Campus levando mais informações a todos os participantes. A maquete de um galpão de uso geral simulando sistemas estruturais metálicos teve público garantido demonstrando a importância do aprendizado teórico-prático.

Palavras-chave: Estruturas metálicas; Impressora 3D; Modelagem. 


\section{INTRODUÇÃO}

A impressão em 3D, segundo Celani (2009), foi uma das técnicas de prototipagem rápida cuja origem se baseava em duas técnicas: a topografia e a foto escultura. A primeira foi um método desenvolvido por Blanther no final do século XIX para a construção de mapas que apresentassem o relevo, e consistiu na impressão de uma série de discos de areia contendo as curvas de nível das cartas topográficas. Já no início da década de 70 , Matsubara (da Mitsubishi Motors) propôs um processo fotográfico. Em que, em regiões de uma camada de foto polímero recoberta por pó de grafite ou areia eram endurecidas após a exposição à luz, e mais tarde as outras partes eram retiradas com a utilização de um solvente. Verificou-se que essa técnica poderia ser empregada para reproduzir as superfícies de fabricação mais complexa, em função da operação da máquina.

As Impressoras 3D vêm encantando o mercado das impressoras conforme proferiu Carnett (2010). Atualmente, encontram-se uma gama de produtos que já foram impressos por uma dessas impressoras com relação a objetos da construção civil (ALBANESIUS, 2012). Quanto à construção em aço, a maior novidade está em uma impressora 3D que imprime com filamentos de aço da London Design Festival, da Arup Associates, no Reino Unido. São inovações tecnológicas que chegaram com pensamento no futuro. Mas, sem se esquecer do presente, o que fazer então? O que está em nossas possibilidades. A proposta deste projeto veio de encontro com essa realidade.

A Optical Fhysics Research Update, um grupo de pesquisa Europeu, desenvolveu pesquisa em análises estruturais para grandes estruturas, percebendo que a densidade das estruturas estudadas poderia ser reduzida drasticamente, se projetadas usando um padrão fractal. Essas pesquisas, conforme a Figura , ainda dependem de um rígido controle de qualidade quanto à impressão, pois não pode haver falhas pois, pequena quantidade de material danificado representa grandes volumes reais que poderiam causar graves problemas. No entanto, já ficou claro que em um futuro não muito longe, as novas tecnologias emergirão efetivamente.

Figura 1 - Estruturas convencionais (a), estruturas com padrões fractais e impressas em 3D (b)
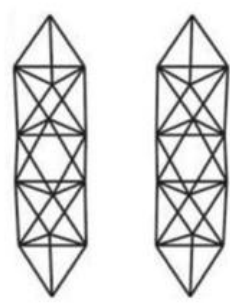

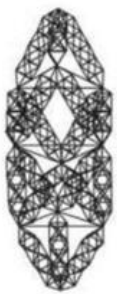

(a)

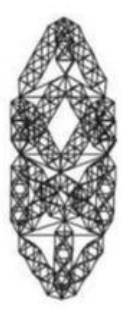

(b)

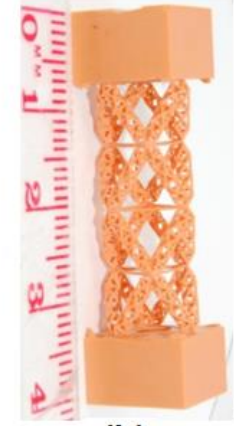

Fonte: COMMISSARIAT, 2012

Sendo assim, a impressão 3D foi um fato que apresentou novas perspectivas educacionais e técnicas, e veio para ficar. A sua popularização possibilitará cada vez mais a criação de inúmeras empresas que exercerão atividades correlatas com esses equipamentos, dentro e fora da construção civil. 
A importância desta pesquisa se refletiu no valor tecnológico das tecnologias de impressão 3D, dos softwares para modelagem de protótipos, bem como, dos equipamentos impressoras 3D, junto às aplicações especializadas como as das estruturas metálicas (ABCEM/CBCA, 2010). Sua importância se refletiu ainda, na oportunidade de interação entre os alunos das disciplinas de Tecnologia das Construções do Ensino Médio Integrado e os alunos de Sistemas Construtivos em Aço e Madeira do Curso Superior em Construção de Edifícios, bem como, dos alunos do Superior em Engenharia de automação e controle do Instituto Federal de Educação, Ciência e Tecnologia de Mato Grosso, Campus Cuiabá - Cel. Octayde Jorge da Silva, unindo todos em um mesmo propósito. O projeto possibilitou conhecer os materiais plásticos há muito tempo utilizados na Construção Civil e agora com novas abordagens para utilização nas impressoras 3D. Neste sentido, este projeto contemplou a pesquisa voltada à ciência das novas tecnologias quanto a equipamentos, a processos construtivos e de materiais, agregando a diversidade de abordagens junto aos alunos e gerando novas oportunidades.

Este projeto visou iniciar os trabalhos em modelagem de estruturas metálicas impressas via impressora 3D com o objetivo de facilitar a visualização dessas estruturas pelos alunos, bem como, de inspirar a iniciativa deles em conhecer essas estruturas idealizando uma especialidade futura. No decorrer da disciplina de Sistemas Construtivos em Aço e Madeira, por exemplo, inúmeros foram os tópicos a serem estudados, como por exemplo, as ligações aparafusadas e/ou soldadas dos sistemas estruturais em aço. No entanto, a curiosidade dos alunos quanto aos processos de fabricação e com relação às soldaduras não pôde ser ignorado. e como essa disciplina não possui laboratório, acabase criando certas dificuldades. Cabe aqui salientar, que trabalhos práticos de soldagem podem se tornar inviáveis junto aos alunos do curso de ensino médio, por exemplo. Sendo assim, a metodologia possibilitou, de forma inicial no presente momento, mas também por meio de projetos futuros, do saneamento de inúmeros questionamentos, e a integração dos alunos dos diversos cursos. Avançando-se no entendimento e na utilização de softwares e equipamentos mais compatíveis com uma formação mais específica e prática, hoje requerida aos jovens profissionais voltados aos estudos das estruturas metálicas.

O objetivo geral da pesquisa foi utilizar a modelagem de estruturas metálicas impressas em impressoras 3D para apoio didático nas disciplinas de Tecnologia das Construções e Sistemas Construtivos em Aço.

\section{METODOLOGIA}

A pesquisa se abrigou nas aquisições de habilidades dos alunos junto aos softwares de modelagem para impressora 3D, e do seu funcionamento para uso em estruturas metálicas; desenvolvimento de protótipo de elementos estruturais unidimensionais como vigas e pilares para sistemas estruturais metálicos, bem como, impressão desses elementos com material plástico tipo filamentos ABS. A transferência de arquivos modelados para a linguagem da impressora 3D por meio dos programas fatiadores também foi analisado.

Geralmente a estrutura de um galpão pode ser decomposta em estrutura principal, estrutura secundária de apoio da cobertura e dos fechamentos laterais, e contraventamentos horizontais e verticais; assim, foram tomados como estruturas de exemplo, os pilares de pórticos, o vigamento metálico em terças e treliças de cobertura. Os galpões, do ponto de vista arquitetônico e estrutural, caracterizam-se por serem edificações com vãos mais generosos que os demais, tendo como pré-requisito os espaços sem obstruções. Os galpões podem ser utilizados para as mais diversas atividades, tais como, 
hangares, espaços de eventos e depósitos em geral, oficinas de serviço, como também, rodoviárias, aeroportos e igrejas (SALGADO, 2011).

A estrutura principal do galpão impresso foi dividida em duas partes, a estrutura horizontal e a vertical. A primeira correspondeu a estrutura que venceu o vão entre os pilares e a segunda, aos próprios pilares, respectivamente. A impressora 3D utilizada pertence ao Laboratório de Telemetria do Departamento de engenharia elétrica e automação, do Campus Cuiabá Octayde Jorge da Silva.

As etapas do projeto estão descritas por meio da Figura .

Figura 2 - Etapas da pesquisa

\begin{tabular}{|c|c|c|c|c|c|c|}
\hline $\begin{array}{l}\text { Planejamen } \\
\text { to inicial } \\
\text { entre } \\
\text { professores } \\
\text { e alunos } \\
\text { das } \\
\text { disciplinas } \\
\text { envolvidas }\end{array}$ & $\begin{array}{c}\text { Pesquisa } \\
\text { bibliográfica } \\
\text { e divisão de } \\
\text { tarefas }\end{array}$ & $\begin{array}{l}\text { Escolha do } \\
\text { software de } \\
\text { modelagem }\end{array}$ & $\begin{array}{c}\text { Estudo do } \\
\text { software e } \\
\text { da } \\
\text { impressora } \\
\text { 3D }\end{array}$ & $\begin{array}{l}\text { Modelagem } \\
\text { dos } \\
\text { elementos } \\
\text { estruturais } \\
\text { unidimensi- } \\
\text { onais }\end{array}$ & $\begin{array}{l}\text { Impressão } \\
\text { dos } \\
\text { protótipos, } \\
\text { verificações } \\
\text { e análises; } \\
\text { ajustes e } \\
\text { correções }\end{array}$ & $\begin{array}{c}\text { Montagem } \\
\text { do sistema } \\
\text { estrutural }\end{array}$ \\
\hline
\end{tabular}

Fonte: Os autores

\section{$3 \quad$ RESULTADOS}

Os resultados da pesquisa foram a impressão das peças e montagem do sistema estrutural do tipo pórtico. Foram impressos: terças, pilares, partes das treliças, encaixes, pinos, furações, contraventamentos verticais e horizontais. A Tabela 1 traz as peças e seus tempos de impressão em horas. A quantidade total de peças foram: 24 terças, 16 peças para pilares; 24 peças para treliças, sendo 8 peças de cada tamanho $(P, M$ e $G) ; 6$ peças de contraventamentos verticais; 8 peças de contraventamentos de extremidade, e por fim, 28 pares de hastes para contraventamentos horizontais, totalizando a impressão da maquete em 203 horas.

Tabela 1 - Tempo de impressão das peças

\begin{tabular}{l|c}
\hline \multicolumn{1}{c|}{ Peças } & Tempo de impressão (horas) \\
\hline Terças & 2,0 \\
\hline Pilares & 2,5 \\
\hline Partes da treliça (P, M, G) & 2,$0 ; 2,8 ; 3,5$ \\
\hline Contraventamento vertical & 2,5 \\
\hline Contraventamento vertical de extremidade & 1,8 \\
\hline Contraventamento horizontal (14 pares) & 2,0 \\
\hline Total & $\mathbf{2 0 3}$ \\
\hline
\end{tabular}

Fonte: Os autores

Todas as peças foram impressas na espessura de $2 \mathrm{~mm}$, exceto as hastes de contraventamento horizontal, com $3 \mathrm{~mm}$. Foram testados os bicos de extrusão de $0,3 \mathrm{~mm}$, $0,4 \mathrm{~mm}$ e $0,5 \mathrm{~mm}$, com filamentos ABS e PLA, em que se optou para a impressão das peças, 
o filamento $A B S$ e o bico de $0,3 \mathrm{~mm}$. A peça de treliça tamanho $P$ refere-se ao encontro do banzo superior com banzo inferior e a extremidade; a peça de tamanho $M$ refere-se à peça do meio, com montante intermediária, e a peça de tamanho $G$ refere-se à peça com montante do oitão.

As etapas de impressão foram inúmeras e com graus de aperfeiçoamento crescente. Da primeira à última etapa de impressão foram analisadas as dimensões altura, largura, comprimento e espessura das peças, bem como a resistência e a estética, principalmente das terças de cobertura, em que as furações, os encaixes e os pinos de fixação das meias tesouras às terças de cobertura, bem como entre os contraventamentos, requereram alguns cuidados e foram desafiadores para os alunos, a Figura 3 possui algumas imagens dessas peças.

Figura 3 - Peças impressas pela impressora 3D. Impressão de treliça (a), cantoneiras soldadas (b), detalhe do pilar (c), furos e pinos na treliça (d), pilar (e), treliça montada (f)

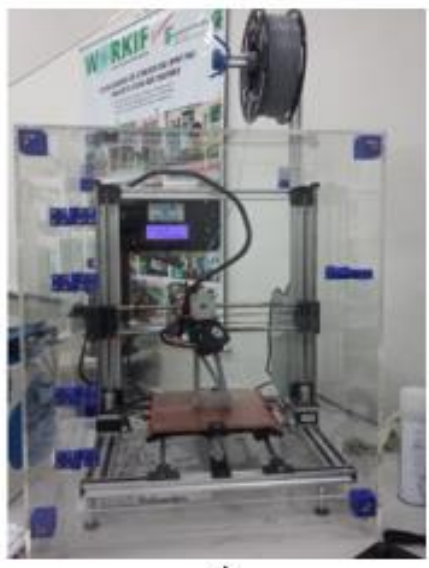

a)

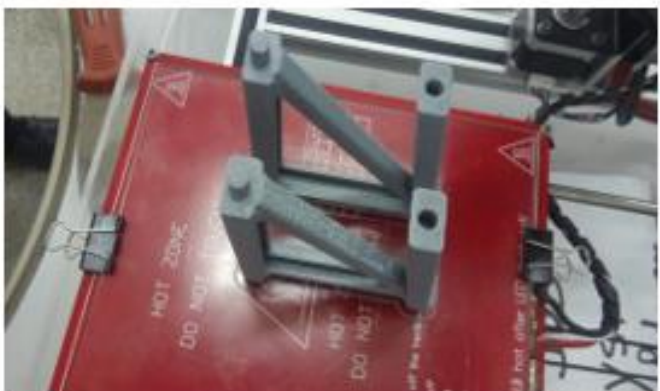

d)

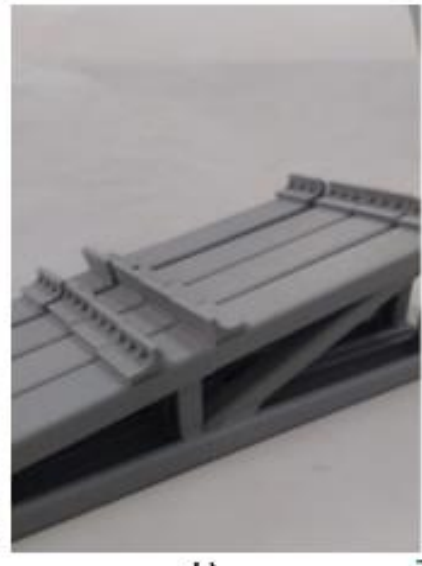

b)

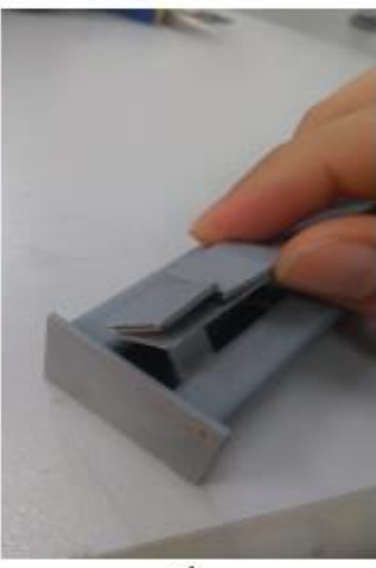

c)

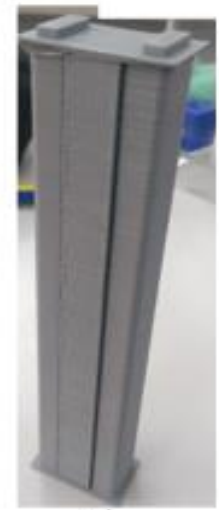

e)

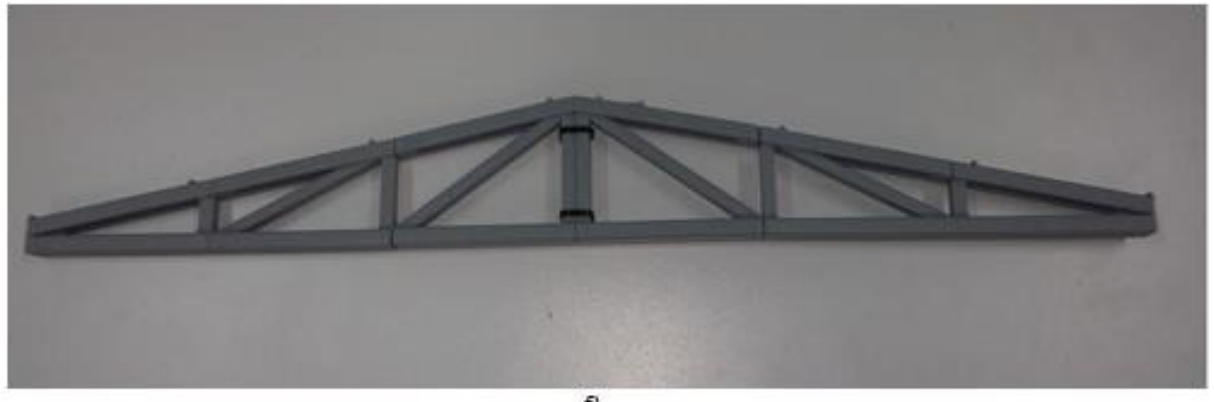

f)

Fonte: Os autores 
Outro ponto importante foi a fixação das terças nas treliças por meio de cantoneiras soldadas, essas ligações foram simuladas conforme mostrado na Figura 3 (b).

Os pilares treliçados foram impressos um a um. Alguns defeitos aconteceram pela falta de aderência entre camadas, no entanto, constatou-se que a temperatura do bico de extrusão, e a temperatura do ar em volta da impressora 3D e das peças no período de impressão eram importantes. $\mathrm{O}$ ambiente do laboratório deveria estar frio, acima dos $25^{\circ} \mathrm{C}$, e o ar circundante dentro do confinamento da impressora, quer dizer, o ar que envolvia as peças durante a impressão em torno de $48^{\circ} \mathrm{C}$ mais ou menos $2^{\circ} \mathrm{C}$; sanadas essas dificuldades alguns defeitos desapareceram.

As subpartes das treliças de cobertura em substituição de peças defeituosas foi uma etapa extra; mesmo assim, ainda ocorreram problemas no nivelamento da mesa de impressão, que em determinado ponto na altura da mesma, perdia seu eixo de alinhamento, causando total desequilíbrio na impressão; este fato quando ocorreu, além da perda da peça, acarretou no entupimento do bico de impressão e sua perda, compreendeu-se que a mesa e as estruturas de suporte vertical da impressora necessitavam de alinhamento e lubrificação constantes.

Nesse labor de se finalizar as impressões, houve a impressão de peças em que algumas subpartes das treliças da cobertura foram impressas duas a duas, em substituições a peças defeituosas. A Erro! Fonte de referência não encontrada. (f) traz ainda a formação de uma treliça da cobertura, em que as divisões em seis partes se deram em função das dimensões da maquete e das dimensões da mesa de impressão tamanho $20 \times 20 \mathrm{~cm}^{2}$ da impressora Plusa.

\subsection{Dificuldades encontradas}

Algumas dificuldades encontradas no desenho das peças metálicas a serem desenhadas no programa Inventor (módulo livre básico - versão estudante) foram superadas com o crescente conhecimento do programa.

A adequação das escalas naturais (em metros) para as escalas de impressão (em milímetros), bem como, as reduzidas medidas de espessuras das chapas dos perfis metálicos e suas variações, valendo-se de que nada poderia ser menor do que os bicos da extrusora, foram superadas pela tomada de decisão de que nesta primeira versão do projeto não seria possível reproduzir uma maquete em modelo reduzido perfeito.

Após as verificações e análises quanto aos tipos de plásticos ABS e PLA, decidiu-se pelo $A B S$, pois as peças ficavam mais resistentes no todo; cabe salientar que desde o início das impressões utilizamos $80 \%$ de preenchimento.

A análise da fixação das peças na base da impressora foi outro fator que gerou expectativas, pois quando a peça se desprendeu, ela se desestabilizou e foi perdida; sendo assim, utilizou-se de fixador para cabelos de médio suporte. Foram testados os fixadores de baixo poder de suporte, mas, nas peças mais altas como os pilares, essa camada adesiva perdeu sua aderência a mais ou menos 2 horas de impressão, quer dizer, praticamente no meio da peça; no entanto, o fixador de alto poder de suporte fixou demais, a ponto de se perder a peça na retirada da base de impressão, mesmo com essa base estando ainda quente ou fria. 


\subsection{Parecer dos alunos quanto ao projeto}

O projeto teve resultado satisfatório para os alunos envolvidos. O aluno bolsista remunerado Matheus Cavalcante concluiu:

"Aprendi muito com esse projeto e estou feliz com os resultados alcançados [...] a convivência com professores e colegas no laboratório foi muito boa e eu pretendo se for possível, continuar fazendo pesquisa, pois assim se aprende e pratica".

Na Figura 4 pode se observar alguns dos estudantes envolvidos no projeto durante o evento Workif no IFMT Campus Cuiabá expondo o galpão com todas as peças montadas.

Figura 4 - Alunos participantes do projeto em exposição durante evento Workif no IFMT Campus Cuiabá

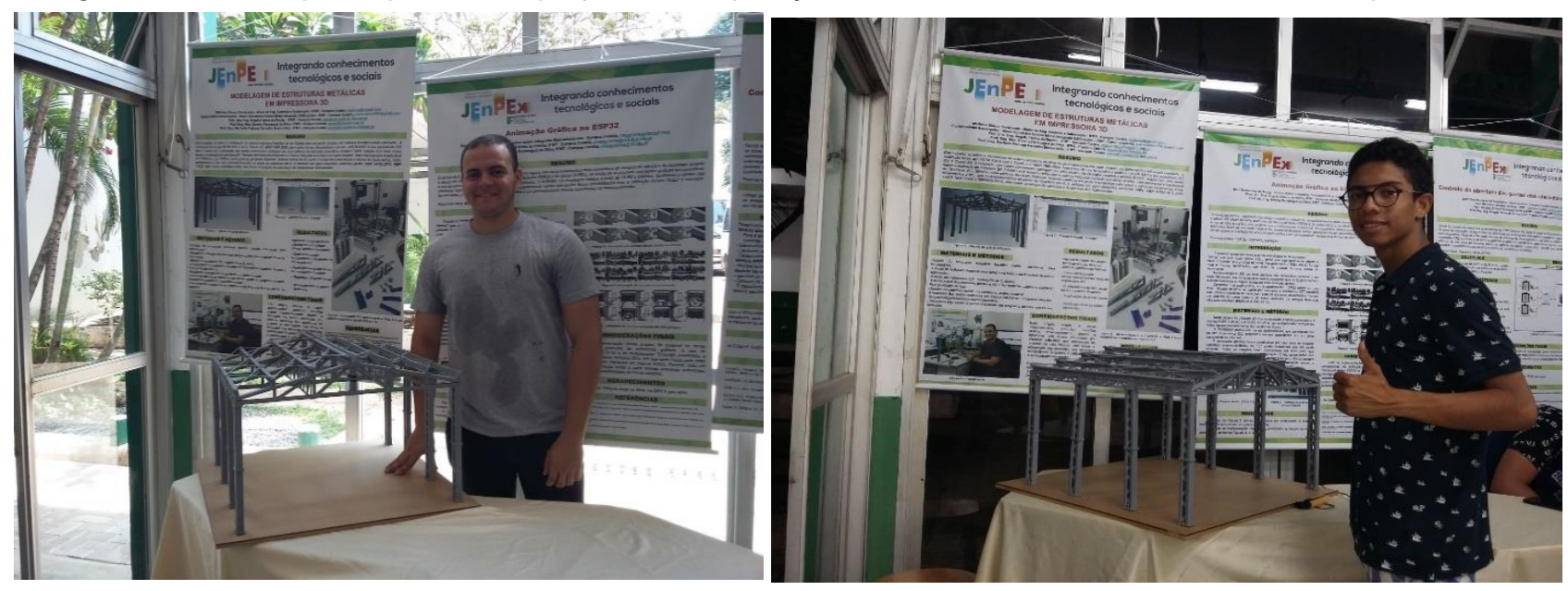

Fonte: os autores

\section{CONSIDERAÇÕES FINAIS}

A abordagem prática dos conhecimentos adquiridos junto aos cursos de Engenharia de Automação e Controle, curso de Tecnologia em Construção de Edifícios e do curso de ensino Médio Integrado em Edificações, promoveu transformação no aprendizado dos alunos e na interação entre os cursos, bem como, na verticalização do ensino no IFMT. Este projeto se utilizou de uma impressora 3D modelo Plusa de uso livre, do software de modelagem Autodesk Inventor versão para estudantes e demais ferramentas para a execução de uma maquete em material ABS. Foi escolhido para simulação um galpão de uso geral em aço pesado de construção. $O$ resultado foi a montagem de um sistema estrutural em perfis $C$ enrijecidos adequadamente contraventados.

Este projeto viabilizou o entendimento e a prática da impressão 3D, e a utilização dos softwares para modelagem de protótipos, junto às aplicações especializadas como as das estruturas metálicas, unindo em um mesmo propósito, o estudo das estruturas metálicas utilizando-se das ferramentas de modelagem e controle. Portanto, este projeto contemplou a pesquisa voltada à ciência, às tecnologias quanto a equipamentos, quanto a processos construtivos e de materiais, agregando a diversidade de abordagens junto aos alunos, gerando maiores oportunidades a seus projetos de vida futuros.

\section{Agradecimentos}

Agradecemos à Diretoria de Pesquisa e Inovação (DPIEX) do Instituto Federal de Mato Grosso, Campus Cuiabá - Cel. Octayde Jorge da Silva pelo apoio financeiro por meio do edital 19/2018. 


\title{
REFERÊNCIAS
}

ABCEM/CBCA. Execução de estruturas em aço - práticas recomendadas. 1 ed., São Paulo: ABECE. 2010.

ALBANESIUS, C. MakerBolt Unveils Replicator 2 3D Printer. PCMag, New York, EUA, 19 set. 2012. Disponível em: https://www.pcmag.com/archive/makerbot-unveils-replicator-23d-printer-302898. Acesso em: 20 abr. 2021.

CARNETT, J. B. Making the Makerbot, A DIY 3-D Printer. Popular Science, Harlan, EUA, 03 ago. 2010. Disponível em: https://www.popsci.com/diy/article/2010-06/makingmakerbot/. Acesso em: 20 abr. 2021.

CELANI, G. Digitalização tridimensional de objetos: um estudo de caso. In: SIGraDi, 2009, São Paulo. Anais... São Paulo: SIGraDi, 2009. p.309-311.

COMMISSARIAT, T. Ultralight fractal structures could bear heavy loads. Physics World, 27 nov. 2012. Disponível em: https://physicsworld.com/a/ultralight-fractal-structures-couldbear-heavy-loads. Acesso em: 20 abr. 2021.

SALGADO, J. Técnicas e práticas construtivas para edificação. 4 ed., São Paulo: Editora Érica. 2011.

\section{MODELING OF METALLIC STRUCTURES PRINTED ON 3D PRINTERS FOR TEACHING SUPPORT IN DISCIPLINES THAT ADDRESS STEEL CONSTRUCTIONS}

\begin{abstract}
The modeling of metallic structures printed on 3D printers for didactic support enriched the activities of the disciplines of Steel Construction Systems and Construction Technologies, approaching the contents taught in a more attractive and innovative way. During these disciplines, numerous topics are to be studied, such as the bolted and / or welded connections of structural steel systems, the model simulation of the assembly of the shed aroused the students' curiosity. As these disciplines do not have a laboratory at Campus Cuiabá, Octayde Jorge da Silva, modeling via software, practical knowledge of 3D printing and simulation of assembly occupied a fundamental space in the learning and valuing of these future professionals. Thus, the modeling of metal structures on 3D printers promoted the verticalization of teaching at the IFMT, bringing high school integrated in Buildings to higher education courses in Automation and Control Engineering and Technology in Building Construction. The project participated in the Workif event promoted by the institution, which disseminated the Campus research taking more information to all participants. The model of a general purpose building simulating metallic structural systems had a guaranteed public demonstrating the importance of theoretical and practical learning.
\end{abstract}

Keywords: Metallic structures; 3d printer; Modeling. 